\title{
Young children's release from proactive interference: The effects of category typicality
}

\author{
DAVID F. BJORKLUND \\ Florida Atlantic University, Boca Raton, Florida 33431 \\ and \\ STEVEN C. SMITH and PETER A. ORNSTEIN \\ University of North Carolina, Chapel Hill, North Carolina 27514
}

\begin{abstract}
Young children's encoding was studied with the release from proactive interference (PI) paradigm. Second-graders' recall decreased over three trials on which stimulus triads were drawn from a given conceptual category. Recall improvement was observed when, on a fourth trial, the stimulus materials were instances of a different conceptual category. However, this release from PI occurred only when the stimulus items were category-typical exemplars of the categories, and not when atypical instances were employed. The results suggest that not only is the dimension of the stimulus materials important in affecting release from PI, but so also is the typicality of the items selected to illustrate that dimension.
\end{abstract}

The extent to which verbal items are judged to be good or poor members of various natural language categories (i.e., their "typicality") has been found to influence strongly the way in which they are processed (Rosch, 1975). It has been demonstrated that adults can reliably rate category typicality (Rosch, 1973, 1975) and that differences in judged typicality influence category verification (Rosch, 1973), same-different reaction time judgments (Rosch, 1975), and various types of recall (Greenberg \& Bjorklund, 1981; Keller \& Kellas, 1978).

That adults encode typical and atypical items differently has been demonstrated in two recent recall experiments. Greenberg and Bjorklund (1981) reported that, under conditions of free recall, college students showed higher levels of recall and clustering for sets of typical relative to atypical exemplars that were matched in terms of word and category frequencies. However, when subjects were given a category label with each to-beremembered word at stimulus input, differences in the free recall of typical and atypical materials were greatly minimized. These data suggest that subjects who were not provided category cues at item presentation did not

This research was supported in part by Grant HD 08459 from the United States Public Health Service. We are grateful to school officials in Montgomery County, North Carolina, for their assistance in obtaining subjects for this study. Thanks are also due Kathleen Corsale for making available to us the stimulus materials used in the Douglas and Corsale (1977) experiment and Howard S. Hock for helpful comments on earlier drafts of this paper. Requests for reprints should be sent to David F. Bjorklund, Department of Psychology, Florida Atlantic University, Boca Raton, Florida 33431. spontaneously encode many atypical items according to their category labels. In addition, Keller and Kellas (1978), using a release from proactive interference (PI) paradigm, demonstrated improved recall after a switch from a series of typical to atypical items (and vice versa) from the same taxonomic category. This improvement, or "release" from PI, was taken to suggest that the encoding of items on the final shift trial differed from the encoding of the previous items. The implications are that category-typical and -atypical items are differentially encoded and that typicality is a meaningful dimension of encoding.

Developmentally, it has been shown that typical items are integrated into children's category structures before atypical items (e.g., Anglin, 1977; Thompson \& Bjorklund, Note 1). For example, Thompson and Bjorklund (Note 1) reported no age differences in the number of adult-defined typical items that kindergarteners, third- and sixth-graders, and college students selected as appropriate category exemplars. However, significant age differences were found in the inclusion of adult-defined atypical instances, with younger children being less likely than older children or adults to select such items as appropriate category exemplars. Furthermore, processing differences between typical and atypical items have been obtained with children on a variety of tasks, including category verification (Rosch, 1973), category priming (Duncan \& Kellas, 1978), and cued recall (Thompson \& Bjorklund, Note 1). The results of these experiments are consistent with the view that natural language categories can be characterized by semantic prototypes and that there are developmental differences in these representations. 
The present experiment was designed to investigate young children's differential encoding of typical and atypical category items in the context of a recall task. Consistent with previous developmental research (e.g., Anglin, 1977; Thompson \& Bjorklund, Note 1), it was proposed that sets of atypical category exemplars would form less cohesive category structures for young children than would sets of typical items. To test this, secondgraders were given lists of typical and atypical category words in a release from PI paradigm. Following a series of "build-up" trials, it was expected that improved recall due to a change in the category of the stimuli would vary as a function of the typicality of the materials. It was predicted that the children would demonstrate release from PI with typical category examples (i.e., shifting from typical exemplars of one category to typical examples of another category), thus replicating the findings of previous studies (e.g., Kail, 1976; Kail \& Schroll, 1974). In contrast, significant release from PI was not expected when atypical items served as stimuli.

\section{METHOD}

\section{Experimental Design}

Second-grade children were presented different triads of words on each of four trials; oral recall was tested on each trial, following a distractor task. Subjects were assigned to one of four groups resulting from the combination of the treatment conditions (experimental vs. control) and materials (typical vs. atypical) variables. Control subjects were presented triads drawn from a single category (animals or food) on each of the four trials, whereas subjects in the experimental group received exemplars of one category on the first three trials and instances from a different category on the last trial. One-half of the subjects in each condition were presented triads that were composed of typical category exemplars, whereas one-half received items that were atypical category examples.

\section{Materials}

In order to obtain items that varied in category typicality, an independent sample of 24 second-grade children (mean age $=7$ years 8 months; 12 boys and 12 girls) not participating in the recall experiment was tested. Each child was given a set of 32 animal words and a second set of 32 food words, with each word printed on a $3 \times 5$ in. card. Subjects were asked to evaluate each word in terms of how "typical" it was of its respective category. The method employed to obtain children's typicality judgments was used successfully by Thompson and Bjorklund (Note 1) and was modified from a procedure first introduced by Rosch (1973).

The children were asked to pretend that there was a person from outer space who knew nothing about the category in question. Subjects were told that they could help this "spaceman" understand the meaning of a particular concept by placing the words in one of three boxes located in front of them. Above each box was a black-and-white schematic "face"; each face had a different facial expression. In the first box, with a smiling schematic face, went "very good" examples of the category; these were words that, even if presented alone, would help the spaceman understand the meaning of the concept. Items in this box would be ones that would come to the subjects' minds first when thinking of the category. In the second box, with a "straight" face, went "OK" examples of the category, and in the third box, with a frowning schematic face, went poor or "not so good" examples of the category. To insure that the children understood the task, subjects were given a practice set of items from the categories of "furniture" and "clothing" to rate in terms of typicality. From these rating data, the 12 highest rated and 12 lowest rated words in the "food" and "animal" categories were selected as the typical and atypical items, respectively. ${ }^{1}$

For each of these four sets of materials, words were arranged into two different subsets of four triads each. These triads were equated as closely as possible in terms of word length and Thorndike-Lorge (1944) word frequencies, and they were printed in .5-in. black letters on $5 \times 7$ in. cards. Each triad was presented equally often on each trial.

\section{Procedure}

Each subject was tested individually, seated at a table opposite a male experimenter. Three practice trials were administered prior to the experimental task. Each trial was begun with a 2-sec presentation of a card on which was drawn an asterisk (with the accompanying verbalization "get ready"). This was followed by a 6-sec presentation of a stimulus triaa that the subject was asked to read aloud. For the next $15 \mathrm{sec}$, subjects rapidly named colors drawn on a color board. Finally, the recall test was initiated with the presentation of a card on which was drawn a question mark (with the accompanying verbalization "remember?"). All children received four such trials of stimulus presentation, distraction (color naming), and recall.

Subjects in the two experimental conditions (receiving either category-typical or -atypical exemplars) were presented examples from a single category (either animals or food) for Trials 1-3. On Trial 4, these subjects received a triad of items from the alternative category, with the typicality level of the category examples remaining constant. Equal numbers of subjects in the experimental groups received items from the animals or food categories on the three initial trials and the final trial. Subjects in the two control conditions (both typical and atypical) received examples from a single category on all four trials, with one-half receiving items from the animals category and the remainder being presented with items from the food category.

\section{Subjects}

The subjects were 96 second-grade children (mean age $=$ 8 years 0 months), 48 boys and 48 girls, from three Montgomery County, North Carolina, elementary schools. Approximately one-half of these children were white and one-half were black. Each school was located in a rural area, and the children were predominantly from lower to middle-class families.

\section{RESULTS}

Table 1 presents mean recall per trial as a function of condition and material. As can be seen, all groups decreased in performance over the first three trials, and only subjects receiving the typical items in the experi-

Table 1

Mean Recall by Condition, Typicality, and Trials

\begin{tabular}{|c|c|c|c|c|c|}
\hline & \multicolumn{4}{|c|}{ Trial } & \multirow{2}{*}{$\begin{array}{l}\text { Trial } 4 \\
\text { Minus } \\
\text { Trial } 3 \\
\end{array}$} \\
\hline & 1 & 2 & 3 & 4 & \\
\hline & \multicolumn{5}{|c|}{ Typical } \\
\hline Experimental & 2.46 & 1.75 & 1.54 & 2.08 & +.54 \\
\hline Control & 2.08 & 1.79 & 1.92 & 1.38 & -.54 \\
\hline \multirow[t]{2}{*}{ Mean } & 2.27 & 1.77 & 1.73 & & \\
\hline & \multicolumn{5}{|c|}{ Atypical } \\
\hline Experimental & 2.21 & 1.79 & 1.92 & 1.75 & -.17 \\
\hline Control & 2.17 & 1.79 & 1.58 & 1.54 & -.04 \\
\hline Mean & 2.19 & 1.79 & 1.75 & & \\
\hline
\end{tabular}


mental group demonstrated a subsequent increase in recall on the fourth trial. Following Kail (1976), the data were evaluated in two analyses. The first analysis examined the recall decrement over Trials 1-3, whereas the second assessed the critical change between Trials 3 and 4 . The analysis of the buildup of PI produced only a significant main effect of trials $[\mathrm{F}(2,184)=9.24$, $p<.001]$, with Newman-Keuls tests $(p<.05)$ indicating that recall on Trial 1 was significantly greater than on Trials 2 and 3. The main effects of condition and materials and all interactions were nonsignificant.

The critical analysis examining Trials 3 and 4, which tested for release from PI, yielded only a significant Condition by Materials by Trials interaction $[F(1,92)=$ $5.44, p<.05]$. Newman-Keuls tests $(p<.05)$ confirmed that only subjects in the experimental group who received the typical items showed a significant increase in recall from Trial 3 to Trial 4. Additionally, subjects in the control group receiving the typical category exemplars showed a significant decrease in recall over the last two trials.

\section{DISCUSSION}

Although all groups of subjects demonstrated the buildup of PI, only experimental subjects receiving typical exemplars showed significant release from PI; no evidence of release was found for children receiving the atypical materials. The increase in recall on the critical shift trial was observed only with a change from typical instances of one category to typical instances of a second category. These results suggest that the second-grade children tested here did not encode the atypical exemplars along a single category dimension, although typical items from the same categories were so encoded. Consistent with predictions, the relations among list items must be sufficiently salient before 7-and 8-year-olds demonstrate categorical encoding as reflected by release from PI.

These findings also suggest an interpretation for some discrepancies found in studies of young children's encoding of evaluative items (i.e., contrasting connotatively "good" vs. "bad" words). Inspection of the materials used in these experiments suggests that the degree to which words were representative of "good" and "bad" categories may be related to whether or not release from PI was found. For example, investigators reporting release from PI with 7- and 8-year-olds (Douglas \& Corsale, 1977; Pender, 1969) seem to have chosen exemplars that are clearly representative of "good" and "bad" categories, whereas those who failed to find release from PI (Cermak, Sagotsky, \& Moshier, 1972; Kail \& Schroll, 1974) seem to have used some items that are less representative of these categories. ${ }^{2}$ This observation, in conjunction with the results of the current experiment, suggests that differences in the typicality of evaluative words may have contributed to the conflicting findings in the literature. More generally, the implication is that release from PI may depend not only on the particular dimension used, but also on how typical or representative the test items are of that dimension.

\section{REFERENCE NOTE}

1. Thompson, B. E., \& Bjorklund, D. F. Children's judgments and processing of typical and atypical category exemplars. Paper presented at the meeting of the Society for Research in Child Development, Boston, Mass., April 1981.

\section{REFERENCES}

Anglin, J. M. Word, object, and conceptual development. New York: Norton, 1977.

Cermak, L. S., Sagotsky, G., \& Moshie r, C. Development of the ability to encode within the evaluative dimensions. Journal of Experimental Child Psychology, 1972, 13, 210-219.

Douglas, J. D., \& Corsale, K. The effects of mode and rate of presentation on evaluative encoding in children's memory. Child Development, 1977, 48, 46-50.

Duncan, E. M., \& Kellas, G. Developmental changes in the internal structure of semantic categories. Journal of Experimental Child Psychology, 1978, 26, 328-340.

Greenberg, M. S., \& BJorkLund, D. F. Category typicality in free recall: Effects of feature overlap or differential category encoding? Journal of Experimental Psychology: Human Learning and Memory, 1981, 7, 145-147.

KAIL, R. V. Children's encoding of taxonomic classes and subclasses. Developmental Psychology, 1976, 12, 487-488.

KAIL, R. V., \& Schroll, J. T. Evaluative and taxonomic encoding in children's memory. Journal of Experimental Child Psychology, 1974, 18, 426-437.

Keller, D., \& Kellas, G. Typicality as a dimension of encoding. Journal of Experimental Psychology: Human Learning and Memory, 1978, 4, 78-85.

Pender, N. J. A developmental study of conceptual, semantic differential, and acoustic dimensions as encoding categories in short term memory (Final report, Project 9-E-070, U.S. Department of Health, Education, and Welfare, Northwestern University). Washington, D.C: U.S. Government Printing Office, 1969.

Rosch, E. On the internal structure of perceptual and semantic categories. In T. E. Moore (Ed.), Cognitive development and the acquisition of language. New York: Academic Press, 1973.

Rosch, E. Cognitive representations of semantic categories. Journal of Experimental Psychology: General, 1975, 7, 192-233.

ThonNdike, E. L., \& LoRgE, I. The teacher's word book of 30,000 words. New York: Teachers College, Columbia University, Bureau of Publications, 1944.

\section{NOTES}

1. The items used in this experiment were: ANIMALS, typical-butterfly, cat, cow, deer, dog, duck, fish, horse, monkey, rabbit, robin, squirrel; atypical-alligator, ant, frog, lion, mouse, pig, shark, skunk, snake, spider, whale, wolf; FOOD, typicalapple, banana, bread, corn, egg, grape, hamburger, hot dog, milk, orange, pie, watermelon; atypical-butter, candy, cheese, cookie, jelly, lemon, marshmallow, onion, peanut, pickle, raisin, tomato.

2. For example, Douglas and Corsale's (1977) "good" words included beautiful, brave, friend, God, good, home, happy, kind, love, music, nice, and sweet, whereas their "bad" words were bad, burn, death, fight, fire, hate, hurt, kill, missing, shoot, sick, and trouble. Kail and Schroll's (1974) "good" words included church, fresh, good, home, live, milk, nice, open, save, and true, and their "bad" words were bad, burn, cold, cut, fall, fear, hate, kill, no, and worry. Our observation of differences in the degree to which the words used in these two experiments are representative of "good" and "bad" categories was supported by rating data we collected. Forty adults used a 7-point scale to rate the words used in the Douglas and Corsale and the Kail and Schroll studies in terms of their connotative evaluation ( 1 = very bad; $7=$ very good). The "good" words used by Douglas and Corsale were rated higher (mean $=6.17)$ than the "good" words used by Kail and Schroll (mean $=5.58)$, whereas the Douglas and Corsale "bad" words received an overall lower rating (mean = 2.05) than did the Kail and Schroll "bad" words (mean = 2.26).

(Received for publication August 16, 1982.) 